\title{
Contribuições ao Debate da Judicialização da Saúde no Brasil
}

Felipe Rangel de Souza Machado(*)

\section{RESUMO}

O texto do art. 196 da Constituição assegura a saúde como "direito de todos e dever do Estado"; entretanto, tal direito não vem sendo garantido na prática. A partir da constatação dessa contradição, grupos da Sociedade Civil buscam na Justiça a materialização de seus direitos até então abstratos. A recente inserção do Poder Judiciário e do Ministério Público no campo da saúde pode ser percebida como uma forma de "judicialização da política". O termo, entretanto, carece de melhor definição que permita identificar de maneira mais precisa a profundidade deste fenômeno no Brasil. Divide-se inicialmente em duas correntes de pensamento: uma que vê no ativismo político do judiciário um empecilho para o desenvolvimento da cidadania e outra que atribui a este fenômeno uma forma de ampliação da própria cidadania. O campo da saúde brasileira tem indícios para subsidiar ambos os argumentos. O que está em jogo, portanto, é justamente o efeito dual da diversidade da judicialização da saúde.

\section{Palavras-chave}

Direito à Saúde; Judicialização.

\section{ABSTRACT}

Brazilian Constitution Article 196 ensures health as "a right to the people and a duty to the State". However, this right has not been guaranteed

(*) Professor-pesquisador da Escola Politécnica de Saúde Joaquim Venâncio (EPSJV/Fiocruz). Doutorando em Saúde Coletiva pelo Instituto de Medicina Social da Universidade Estadual do Rio de Janeiro (IMS/UERJ). E-mail: <felipemachado@ fiocruz.br>. Recebido em 25.5.07. Reapresentado em 20.5.08. Aprovado em 30.5.08. 
in regular basis. Considering this contradiction, groups in the Civil Society has been seeking in Courts the materialization of their rights. Recently, Judiciary Power and the Prosecuting Counsel have been acting in the field of health what could be perceived as a form of "judicialization of this politics." This term, however, needs better definition to identify more precisely the depth of this phenomenon in Brazil. Initially it can be distinguished two schools: one that sees the political activism as a legal obstacle to the development of citizenship and other that attaches to this phenomenon a form of enhancing the own citizenship. Brazilian health sector has conditions to support both arguments. Therefore, the most important is precisely the double effect of the diversity of the judicialization of health.

\section{Keywords}

Judicialization; Right to Health.

\section{INTRODUÇÃO}

A Constituição Federal do Brasil é um marco significativo no processo de democratização do país, por trazer em seu escopo jurídico-legal a afirmação da cidadania. Mais do que apenas liberdades civis, na nova cidadania, estão incluídas diversas ações que devem ser prestadas pelo Estado. Exemplo disso é o texto do art. 196 da Constituição que assegura a saúde como "direito de todos e dever do Estado, garantido mediante políticas sociais e econômicas que visem à redução do risco de doença e de outros agravos e ao acesso universal e igualitário às ações e serviços para sua promoção, proteção e recuperação".

Numa primeira aproximação, tal assertiva pode parecer algo natural, na medida em que a saúde diz respeito à vida, e uma das principais funções do Estado é garantir a vida dos cidadãos. Ao contrário, nenhuma obviedade cabe na apreciação deste breve artigo. Primeiro, porque historicamente o Estado brasileiro privou grande parcela de sua população do direito ao acesso aos serviços e bens de saúde ${ }^{(1)}$ e, segundo, porque são poucos os países do mundo que nesta época orientavam a organização do setor saúde por uma lógica pública universalista ${ }^{(2)}$.

(1) Antes da Constituição de 1988 o acesso aos serviços públicos de saúde era exclusivo aos trabalhadores com vínculos empregatícios formais.

(2) Em alguns países reconhecidamente democráticos, a exemplo do Canadá e da Inglaterra, o sistema de saúde se pauta pelo princípio universalista de acesso. Contudo, esta é a realidade em apenas uma parte dos países democráticos modernos. No modelo de saúde norte-americano, por exemplo, apenas os miseráveis comprovados, os aposentados e os veteranos de guerra têm direito a algum tipo de ação gratuita em saúde. O que, por si só, sequer configura um direito, mas simplesmente um benefício em função de determinada condição social. 
No Brasil, o Sistema Único de Saúde (SUS) constitui um dos principais avanços em relação ao desenvolvimento de políticas públicas do Estado de caráter universalista. Apesar da tentativa de desmonte e sucateamento dos serviços públicos, implementada no bojo do processo de remodelação neoliberal do Estado brasileiro a partir do governo Collor de Mello, o SUS, ao contrário de outros setores, manteve-se como uma política consistente. Uma das explicações possíveis para a afirmação do Sistema como política pública de Estado, mesmo diante da rápida reestruturação do Estado brasileiro, devese, sobretudo, à organização do campo da saúde e sua articulação com setores importantes da sociedade, motivos pelos quais o sentido do SUS, previsto na Carta Constitucional, ainda é mantido vivo no horizonte das práticas de saúde coletiva. Todavia, ainda resta um longo caminho pela frente para a efetiva materialização dos preceitos constitucionais relativos à saúde pública no Brasil. É nesse sentido que a discussão em torno dos limites e possibilidades do SUS - concretamente, uma das mais completas e consistentes propostas de política pública social já implementadas no país - tem evoluído e se aprofundado.

Tais limites encontrados pelo SUS evidenciam a seguinte contradição: a própria "Constituição Cidadã", assim declarada no ato de sua proclamação, tem como finalidade garantir direitos na área da saúde que, na prática, não são assegurados plenamente. A partir desta contradição, diversos grupos da sociedade têm buscado a materialização de seus direitos constitucionais, articulando novas estratégias de luta no campo do Direito, esfera que tem se apresentado como meio efetivo para superar a contradição mencionada, entre os direitos constitucionais, até então abstratos, e as práticas concretas das políticas públicas de saúde.

\section{A ATUAÇÃO DO DIREITO NO CAMPO DA SAÚDE}

A atuação de novos agentes (por exemplo, grupos organizados da sociedade civil e os próprios Conselhos de Saúde) no campo do direito para a garantia da saúde representa uma tendência ainda não hegemônica de mudança do paradigma de cidadania vigente, caracterizado pela mera delegação eleitoral, para uma participação ativa ou indireta nos rumos das políticas públicas. Esta nova participação tem se orientado pela noção do que podemos chamar de cidadania complexa(3), segundo a qual "a atividade dos agentes do sistema jurídico, bem como a dos agentes sociais em direção a ele, são interpretadas enquanto ação política que busca, no plano da aplicação do direito, soluções e resoluções para dilemas oriundos de conflitos sociais"(4).

(3) A "cidadania complexa" ampliaria a cidadania para além da questão da representação política, pois encontraria em outras instâncias, como no Poder Judiciário, novas formas de atuação política, ou seja, acionariam o Judiciário para acessar o Executivo. Isto ocorre, por exemplo, com a proposição de Ações Diretas de Inconstitucionalidade e de Ações Civis Públicas e com a impetração de Mandados de Segurança e de Intimação. Este tema será tratado especificamente na seção posterior. (4) EISENBERG, José. Pragmatismo, direito reflexivo e judicialização da política. In: VIANNA, Luiz Jorge Werneck (Org.). A democracia e os três poderes no Brasil. Belo Horizonte: UFMG, 2002. p. 46. 
A estratégia dos sujeitos de garantirem seus direitos recorrendo ao Poder Judiciário tem acontecido, sobretudo, em duas frentes distintas: uma individual e outra coletiva. A busca pela garantia do direito à saúde tem passado pela atuação de diversas instâncias judiciais: o Poder Judiciário, o Ministério Público e a Defensoria Pública. Além desses, embora em escala reduzida, soma-se a atuação de escritórios particulares de Advocacia ${ }^{(5)}$. Podemos, considerando a ação de cada uma dessas instituições, distinguir os seus diversos tipos de atuação.

Primeiramente, destaca-se a decisiva presença do Poder Judiciário, instituição responsável pelo julgamento das questões referentes à concessão ou negação de determinado pleito. Tal presença se torna manifesta na medida em que "a linguagem e os procedimentos do direito (...) mobilizam o Poder Judiciário para o exercício de um novo papel, única instância institucional especializada em interpretar normas e arbitrar sobre sua legalidade e aplicação, especialmente nos casos sujeitos à controvérsia"(6).

Outros dois grupos principais atuam como provocadores do Poder Judiciário. O primeiro deles representa os interesses individuais; inserem-se neste campo a Defensoria Pública e os escritórios privados de advocacia ${ }^{(7)}$. Suas demandas dizem respeito aos direitos que os indivíduos acreditam que o Estado deveria garantir e, geralmente relacionam-se à compra de determinados insumos necessários à manutenção ou recuperação da saúde dos indivíduos. ${ }^{(8)} \mathrm{O}$ segundo grupo, composto basicamente pelo Ministério Público ${ }^{(9)}$, representa os interesses coletivos,

(5) Conforme estudo realizado por Messeder, Osório-de-Castro e Luiza (2005) a respeito da expedição de Mandados de Segurança para a garantia imediata de acesso a medicamentos, os escritórios particulares de Advocacia têm se detido numa atuação voltada à defesa de associações de portadores de patologias e organizações não governamentais. Tais dados são referentes à pesquisa realizada entre 1991 e 2002.

(6) VIANNA, Luiz Jorge Werneck; MELO, Manuel Palácios Cunha; CARVALHO, Maria Alice Rezende de; BURGOS, Marcelo Baumann. Corpo e alma da magistratura brasileira. Rio de Janeiro: Revan, 1997. p. 20.

(7) Apesar de o Ministério Público não estar incluído neste grupo, porque constitucionalmente tem a função de defender interesses coletivos, alguns MPs do Brasil têm atuado na defesa dos interesses individuais. Outros, embora já tenham atuado de semelhante modo, abandonaram esta prática há algum tempo.

(8) Hoje, pleiteiam-se principalmente medicamentos, fraldas para idosos e determinados tipos de leite em pó para crianças com certas doenças. Porém, além desses, consensualmente considerados legítimos, observam-se também pedidos de medicamentos ainda não testados no mundo (como o pó de medula óssea), determinados tipos de xampu e operações para mudança de sexo. Interessante notar que independentemente do tipo de ação o mesmo artigo 196 é invocado. Está em tramitação na Câmara dos Deputados um projeto de lei que delimita o que é ação em saúde, o que facilitará a decisão do juiz em determinados casos. Entretanto, corre-se o risco de voltarmos a uma concepção de saúde puramente biológica, negando inclusive o artigo $3^{\circ}$ da Lei Orgânica da Saúde que estabelece como fatores determinantes e condicionantes da saúde "a alimentação, a moradia, o saneamento básico, o meio ambiente, o trabalho, a renda, a educação, o transporte, o lazer e o acesso aos bens e serviços essenciais".

(9) Segundo Messeder, Osório-de-Castro e Luiza (2005), alguns escritórios privados de advocacia, que lidam com ONGs e determinadas associações da sociedade civil, também têm uma atuação voltada para a defesa dos direitos coletivos, embora ainda em escala muito reduzida. 
O Ministério Público(10) (MP) é uma instituição permanente incumbida da defesa: da ordem jurídica, do regime democrático, dos interesses individuais indisponíveis (ditos imanentes à personalidade humana e pertencentes a uma coletividade) e dos direitos coletivos e difusos (caracterizados por abranger não indivíduos ou grupos singulares, mas aqueles que possuem necessariamente algo em comum) $)^{(11)}$. Sua competência diz respeito ao cuidado pelos serviços de relevância pública e tem por função principal zelar pela promoção dos direitos constitucionais, sendo que, dentre estes está o direito à saúde (entendido como um direito individual, coletivo e difuso, conforme o artigo 197 da Constituição). Além disso, tem-se observado o papel do MP na busca pelo direito à saúde, tanto como instituição provocadora da Justiça quanto como espaço extrajudicial de resolução de conflitos.

Diversos trabalhos ${ }^{(12)}$ têm demonstrado recentemente a atuação desta instituição na busca pela garantia dos direitos sociais. No campo da saúde, seu desempenho está ligado aos grupos organizados da sociedade. Em dissertação de mestrado(13), pudemos observar que os Conselhos de Saúde têm no Ministério Público um excelente parceiro de luta. Além dos Conselhos, vê-se a atuação conjunta com associações de patologias específicas, como a associação dos renais crônicos, em busca da melhoria ou da implantação de determinados serviços de saúde. Neste sentido, é importante reparar a forma de atuação do MP. Seu principal instrumento é a Ação Civil Pública. Entretanto, esta instituição tem se detido nas fases pré-processuais, ou extrajudiciais, para a resolução de seus conflitos, conforme apontam Vianna e Burgos ${ }^{(14)}$, de maneira que poucos inquéritos chegam a se transformar em Ações Civis Públicas. Muitas disputas levadas a cabo por esta instituição têm sido solucionadas com a assinatura de um Termo de Ajustamento, espécie de compromisso entre as partes em desacordo que visa estabelecer a

(10) Art. 127 da Constituição Federal de 1988.

(11) Mais propriamente, os direitos coletivos e difusos representam interesses que transcendem o âmbito de proveito individual, atingindo área de benefício de um grupo indeterminado de pessoas, e que, inegavelmente, possuem preponderante carga de natureza pública.

(12) Ver, a este respeito: DALLARI, S. G. Uma nova disciplina: o direito sanitário. Revista de Saúde Pública, São Paulo, v. 22, n. 4, p. 327-334, 1998; MELAMED, Clarisse; RIBEIRO, José Mendes. O inquérito civil público sobre a Saúde. ENSP/FIOCRUZ, 1995; TORRES-FERNANDES, Marilia de Castro. Ministério Público em São Paulo: eficácia da função institucional de zelar pelo direito à saúde. Dissertação (Mestrado), Universidade de São Paulo, São Paulo, 1999.

(13) MACHADO, Felipe Rangel de Souza. Direito à saúde, integralidade e participação: um estudo sobre as relações entre Sociedade e Ministério Público na experiência de Porto Alegre. Dissertação (Mestrado). Instituto de Medicina Social, Universidade do Estado do Rio de Janeiro, Rio de Janeiro, 2006.

(14) VIANNA, Luiz Jorge Werneck; BURGOS, Marcelo Baumann. Revolução processual do direito e democracia progressiva. In: VIANNA, Luiz Jorge Werneck (Org.). A democracia e os três poderes no Brasil. Belo Horizonte: UFMG, 2002. p. 442. 
responsabilidade dos gestores na correção de problemas específicos, além de compreender propostas claras de possíveis soluções, estipulando prazos de execução. No caso estudado, da atuação dos MPs Federal e Estadual de Porto Alegre no campo da saúde, em cinco anos desta atuação, apenas duas ações civis foram levadas ao Poder Judiciário.

A receptividade do Poder Judiciário tem se mostrado diversa em relação às ações demandando direitos individuais ou direitos coletivos. Em geral, obtém-se mais resultados em pleitos individuais, onde o processo diz respeito à compra de um bem específico ou ao pagamento de um procedimento médico-hospitalar. Nos casos dirigidos pelo Ministério Público na área da saúde, o Poder Judiciário tem evitado opinar sobre estas questões, possivelmente porque tais ações incidem diretamente na condução das políticas públicas para o setor e demandam maior gasto público.

Em estudo sobre ações requerendo medicamentos para o combate da AIDS, Gouvêa ${ }^{(15)}$ mostra que o ano de 1996 foi um marco de mudança de postura no Poder Judiciário. O autor argumenta que antes deste ano todas as ações (individuais e coletivas) encaminhadas à justiça eram sumariamente negadas, ao passo que a partir desta data, quase todos os pedidos passaram a ser aceitos pelo Poder Judiciário. A justificativa inicial para a negação do direito baseava-se na interpretação do art. 196 da Carta Magna meramente como uma norma programática, "insuscetível de produzir efeitos jurídicopositivos"(16). A questão relevante que se apresenta é a respeito do motivo da mudança de postura do Poder Judiciário. Primeiramente, como não poderia deixar de ser, destaca-se a criação da Lei n. 9.313/96 que garante a distribuição gratuita e universal de anti-retrovirais. Esta obrigação é conjunta e solidária entre a União, Estados, Municípios e o Distrito Federal. Por não ter definido especificamente de quem era a atribuição da dispensação destes medicamentos, a maior parte das ações incidem sobre os Estados, conforme estudo de Messeder, Osório-de-Castro e Luiza(17). Estes autores argumentam que, como os medicamentos para tratamento da AIDS são fornecidos ou pelo Governo Federal ou pelos Estados para que os Municípios os distribuam, as ações deveriam, portanto, incidir sobre os Municípios. "Este proceder implicaria também uma maior responsabilização das autoridades sanitárias dos municípios, intimadas a cumprir a lei."(18)

(15) GOUVÊA, Marcos Masilli. O direito ao fornecimento estatal de medicamentos. Revista Forense, Rio de Janeiro, v. 370, p. 103-134, 2003.

(16) Id. Ibid., p. 105.

(17) MESSEDER, Ana Márcia; OSORIO-DE-CASTRO, Cláudia Garcia Serpa; LUIZA, Vera Lúcia. Mandados judiciais como ferramenta para garantia do acesso a medicamentos no setor público: a experiência do Estado do Rio de Janeiro. Cadernos de Saúde Pública, Rio de Janeiro, v. 21, n. 2, p. 525-534, 2005.

(18) Id. Ibid., p. 531. 
Os autores demonstram que, a partir de 1997, com a estruturação do Programa Nacional de DST/AIDS e a distribuição gratuita e organizada dos medicamentos de combate à AIDS, houve uma diminuição expressiva de processos judiciais nesta área. Ao que tudo indica, a grande quantidade de ações para garantia de medicamentos no tratamento da AIDS proporcionou uma ampliação da própria lei, provocando tanto o Legislativo para a criação desta lei, como o Executivo para a adoção desta política. Contrariamente à perspectiva de que esta interferência do Poder Judiciário provocaria uma retração da cidadania (por diminuir o peso das instâncias eleitas do Estado de Direito, isto é, o Poder Legislativo e o Poder Executivo), no caso aqui destacado, ela possibilitou a ampliação desta (ainda que não pelas vias da democracia representativa tradicional), mediando o acesso dos cidadãos às instâncias legisladoras e executoras das leis (pela via de uma democracia, por assim dizer, mais participativa). Trata-se, enfim, da ampliação da cidadania, por meio da participação, embora restrita, de grupos organizados da sociedade, que passam a desempenhar o papel de agentes provocadores da justiça. Este tipo específico de participação proporciona um acesso indireto dos cidadãos às instâncias formuladoras das leis.

Esta ampliação do Poder Judiciário, segundo Cappelletti(19), viria a sanar as dificuldades que os Poderes Executivo e Legislativo apresentam em vocalizar a vontade popular. Estas instituições operariam como "complexa estrutura política, em que grupos variados procuram vantagens, manobrando entre vários centros de poder [e] o que daí resulta não é necessariamente a enunciação da vontade da maioria [...] e sim, freqüentemente, o compromisso em ter os grupos com interesses conflitantes"(20).

A princípio, o surgimento de uma lei específica relativa ao fornecimento de medicamentos anti-retrovirais, por delimitar assim o campo de aplicação da lei, poderia ter significado a diminuição da discricionariedade dos juízes e, conseqüentemente, a diminuição da interferência do Poder Judiciário no campo da saúde. No entanto, o que se observou foi justamente o oposto. Se antes o art. 196 era considerado uma norma programática, a partir do ano de 1997 o mesmo texto passou a ser reconhecidamente uma norma constitucional de plena eficácia. Segundo Gouvêa(21), "impulsionadas por esta mudança no padrão decisório, ações versando o fornecimento de medicamentos para outras doenças foram se tornando cada vez mais freqüentes e com maior porcentagem de êxitos".

Esta interferência do Poder Judiciário na política não é um fenômeno particular ao Brasil. Tate e Vallinder (22) identificam a interferência de manda-

(19) CAPPELLETTI, Mauro. Juízes legisladores? Porto Alegre: Sergio Antonio Fabris Editor, 1993. $134 \mathrm{p}$.

(20) Id. Ibid., p. 95.

(21) GOUVÊA, Marcos Masilli, op. cit., p. 106.

(22) TATE, C. Neal. Why the Expansion of judicial power? In: ; VALLINDER, Torbjorn (Org.). The global expansion of judicial power. New York, London: New York University Press, 1995. 
dos dos tribunais em suas políticas públicas em quase todos os países americanos nos últimos anos. Além disso, os autores ressaltam que mesmo os países-membros da União Européia já tiveram suas políticas alteradas devido à ingerência da Corte Européia.

No Brasil, a liminar tem sido o instrumento principal utilizado pelo Poder Judiciário para garantir o acesso imediato de um cidadão a um determinado bem ou serviço de saúde. Ela pode ser concedida em função de Mandado de Segurança (art. 5ำ LXIX, CF/88) impetrado por algum indivíduo que tenha seu direito líquido e certo não garantido por alguma instância ou autoridade pública, ou também em função de uma Ação Civil Pública (art. 129, III, CF/88) iniciada pelo Ministério Público (ver quadro abaixo).

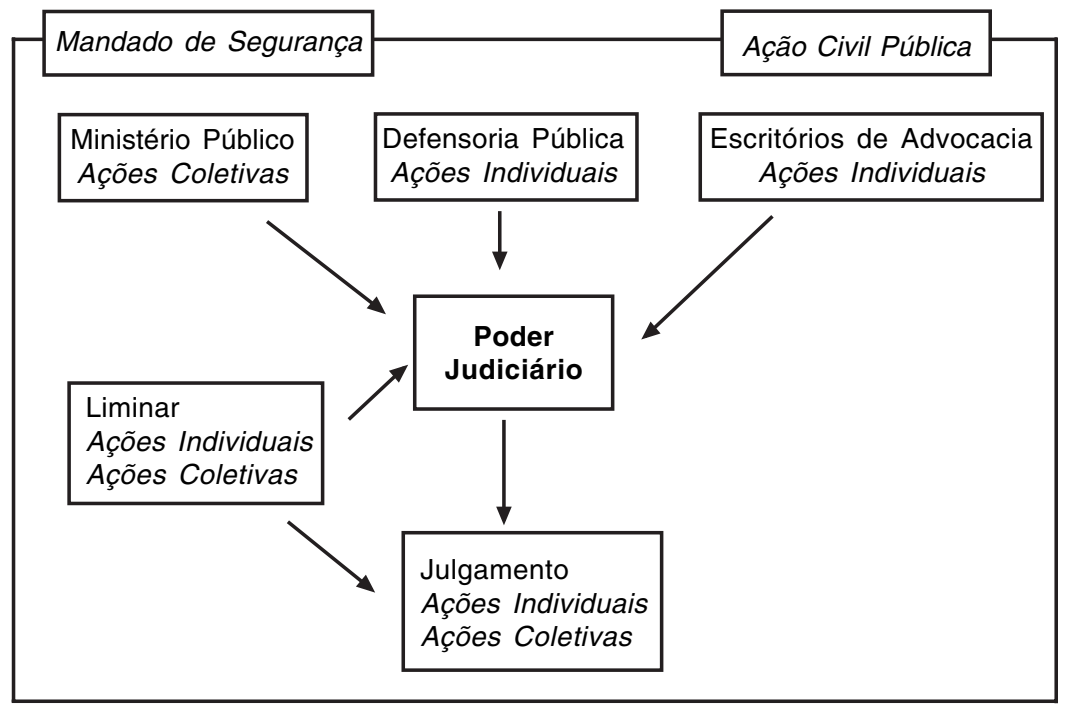

Em dissertação de mestrado, constatamos que, no caso do Poder Judiciário do Rio Grande do Sul, foram raríssimas as liminares concedidas a pedido do MP. Prática oposta adotada em relação às demandas individuais na mesma localidade. Muitas críticas, todavia, decorrem desta opção do Judiciário. "Autoridades e diretores de unidades médicas afirmam, que, constantemente, uma ordem judicial impondo a entrega de remédio a um determinado postulante acaba por deixar sem assistência farmacêutica outro doente, que já se encontrava devidamente cadastrado junto ao centro de 
referência."(23) Além disso, em outros casos, obriga-se o Estado a arcar com o pagamento imediato de determinados bens sem que os mesmos passem por um processo de licitação, causando um desequilíbrio avassalador nas contas públicas, e, principalmente, no orçamento destinado à saúde.

Esta inserção do Poder Judiciário e do Ministério Público no campo da saúde pode ser percebida como um forte indício de "judicialização da política" (forma abreviada de nomear a "expansão do Poder Judiciário" - Tate e Vallinder(24)). Esta expressão, entretanto, não tem aparecido para descrever a inserção do Poder Judiciário no desenvolvimento da política de saúde. Isto ocorre, em parte, pela falta de estudos sistemáticos das Ciências Humanas e Sociais que permitam fazer tal afirmação. A seguir, serão discutidos aspectos teóricos e conceituais que vêm permeando a análise sobre judicialização no campo brasileiro. Retomá-la, portanto, constitui importante passo para uma melhor compreensão de um fenômeno que vem ocorrendo no campo da política de saúde brasileira nos últimos anos.

\section{DEBATE TEÓRICO - A JUDICIALIZAÇÃO, O DIREITO E A DEMOCRACIA}

O termo "judicialização" ganhou corpo a partir da publicação do trabalho dos norte-americanos Tate e Vallinder ${ }^{25)}$, The Global Expansion of Judicial Power, no qual defendem a tese de que judicialização envolve essencialmente tomar algo sob a forma do processo jurídico, tanto em termos de transferência das decisões sobre direitos da legislatura, do gabinete, do serviço civil para as cortes, como em termos da disseminação dos métodos e decisões judiciais para além da esfera judicial propriamente dita.

De acordo com a discussão realizada por Tate(26), na qual o autor pretende desvendar as condições políticas e os seus valores implícitos na promoção do processo de judicialização, existem algumas condições necessárias para que possamos identificar na realidade a expansão do Poder Judiciário. Dentre essas condições, importa-nos retomar três delas: 1) existência de um regime democrático; 2) separação dos poderes (coexistência e independência entre eles); e 3) política de direitos (resguardar os direitos das minorias frente à vontade da maioria). Entretanto, mesmo coexistindo na realidade uma gama destas condicionantes, não seria possível afirmar a existência da judicialização. A judicialização da política, para o autor, requer que os juízes tenham atitudes pessoais, preferências políticas e valores apropriados $^{(27)}$. A judicialização, neste sentido, depende acima de tudo da opção

(23) GOUVÊA, Marcos Masilli, op. cit., p. 113.

(24) TATE, C. Neal; VALLINDER, Torbjorn, (Org.). op. cit.

(25) Id. Ibid.

(26) TATE, C. Neal, op. cit., p. 27-37.

(27) Id. Ibid., p. 33. 
dos juízes de participarem do processo de decisão política, no lugar de simplesmente deixarem que as decisões sejam tomadas nos órgãos e instituições usualmente competentes para tanto.

Segundo Maciel e Koerner(28), para o estudo do caso brasileiro, este termo necessita de melhor definição, que permita identificar mais precisamente a profundidade deste fenômeno no Brasil. Para estes autores, sua utilização tem ocorrido, em muitos casos, de forma até mesmo paradoxal, o que não permite a delimitação de seu conteúdo. Por isso, propõem uma diferenciação da interpretação dada à judicialização, a partir de duas matrizes teóricas influentes no cenário nacional. A primeira, representada por Rogério Arantes, que

"utiliza a idéia de judicialização da política para referir-se ao ativismo voluntarista do Ministério Público e suas implicações negativas seja para a integridade das funções políticas das instituições representativas, ou ainda, para a própria manutenção da independência funcional da instituição."(29)

A segunda matriz, segundo eles, representada por Vianna, trata a judicialização "em termos de procedimentalização do direito e da ampliação dos instrumentos judiciais como mais uma arena pública a propiciar a formação da opinião e o acesso do cidadão à agenda das instituições políticas"(30).

Se analisarmos o fenômeno da saúde no Brasil, encontraremos argumentos que justifiquem ambas as posições. Talvez de um lado estejam principalmente os gestores de saúde, que abarrotados de Mandados de Prisão, mudam as salas de seus gabinetes para não serem encontrados. Por outro lado, determinados grupos organizados da sociedade civil vêem no Poder Judiciário uma forma de acesso aos seus direitos. Conforme sustenta Cappelletti(31), muitos grupos que não encontram escuta nos poderes políticos têm no Poder Judiciário uma imensa possibilidade de acolhida. Além disso, como lembra Vianna ${ }^{(32)}$, o "judicial review e a afirmação de leis fundamentais que impõem limites à regra da maioria, abrem para os cidadãos novos lugares de representação da sua vontade". Além disso, um dos aspectos da judicialização descritos por Vallinder ${ }^{(33)}$ diz respeito à revisão jurídica das ações da legislatura e do Executivo, conforme a Constituição do país. Esta premissa possibilita ao Poder Judiciário impor limites constitucionais à ação

(28) MACIEL, Débora Alves; KOERNER, Andrei. Sentidos da judicialização da política: duas análises. Lua Nova, São Paulo, n. 57, p. 113-133, 2002.

(29) Id. Ibid., p. 117.

(30) Id. Ibid.

(31) CAPPELLETTI, Mauro, op. cit., p. 99.

(32) VIANNA, Luiz Jorge Werneck; BURGOS, Marcelo Baumann, op. cit., p. 341.

(33) VALLINDER, Torbjorn. When the courts go marching. In: TATE, C. Neal; VALLINDER, Torbjorn (Org.), op. cit., p. 13-26. 
dos outros dois Poderes, protegendo-os de infringir sua própria determinação, ou ainda de excederem ou não realizarem à altura suas atribuições.

Impor limites aos outros dois poderes é algo claro na democracia, condição presente no sistema de check and balances; entretanto, o fato de o Poder Judiciário representar uma limitação à maioria pode parecer algo incompreensível. Contudo, voltando à Cappelletti(34), "parece bem evidente que a noção de democracia não pode ser reduzida a uma simples idéia majoritária. Democracia significa também participação, tolerância e liberdade".

Uma discussão sobre democracia extrapolaria em muito os limites deste texto, mas ainda assim, cabe pontuar alguns traços relevantes a esse assunto que permeiam a discussão de judicialização. O primeiro ponto a ser destacado está presente no importante livro de Cappelletti(35) "Juízes Legisladores". Uma pergunta que poderíamos formular a partir dele seria se a criação de leis por parte do judiciário, judiciary law, teria interferência sobre o processo democrático, tanto no sentido de sobrepujar as tarefas do legislativo, quanto sobre a própria legitimidade das leis criadas por aquela instituição. A este questionamento Cappelletti(36) escreve:

"um judiciário razoavelmente independente dos caprichos, talvez momentâneos, da maioria, pode dar uma grande contribuição à democracia; e para isso em muito pode colaborar um judiciário suficientemente ativo, dinâmico e criativo, tanto que seja capaz de assegurar a preservação do sistema de checks and balances, em face do crescimento dos poderes políticos, e também controles adequados perante os outros centros de poder (não governativos ou quase-governativos), tão típicos das nossas sociedades contemporâneas."

Para compreender melhor tais questões, deve-se retornar a algumas premissas presentes no início do texto do autor. Para Cappelletti/37), "é natural que toda interpretação seja criativa e toda interpretação judiciária law making". O ponto principal está no grau, modos, limites e legitimidade da criatividade judicial. $\mathrm{O}$ autor retoma três regras fundamentais presentes nos processos judiciais sem as quais o Poder Judiciário deixaria de ser uma instância legítima de resolução de conflitos, tornando-se, assim, um tribunal extremamente autoritário. A primeira destas regras exige que o juiz não decida sobre qualquer caso que ele mesmo seja um dos interessados e participantes. A segunda, impõe o "caráter contraditório do processo, isto é, que todas as partes da relação ou estado objeto do juízo, pessoalmente ou por meio de seus representantes, tenham efetiva oportunidade de se defender e, assim, uma adequada oportunidade de serem ouvidas por um juiz parcial(38)".

(34) CAPPELLETTI, Mauro, op. cit., p. 107.

(35) Id. Ibid.

(36) Id. Ibid., p. 107.

(37) Id. Ibid., p. 24.

(38) Id. Ibid. p. 75. 
A terceira, ao contrário do que ocorre nos procedimentos do Legislativo e do Executivo, requer uma atitude passiva, na medida em que uma ação não pode ser iniciada pelo próprio juiz; o Poder Judiciário só pode decidir mediante uma provocação externa.

Sob o ponto de vista da atuação até certo ponto limitada do Poder Judiciário, seria inconsistente afirmar que a judiciary law atuaria de forma negativa sobre os preceitos democráticos. Não seria correto afirmar nem que estas leis substituiriam ou que teriam a mesma abrangência das leis do Poder Legislativo. Dentre as limitações descritas por Cappelletti(39), às leis do Judiciário, destaca-se o fato de que "quando os juízes tomam certas decisões de caráter político lato sensu têm a sua disposição escassos instrumentos para lhes assegurar a execução, e geralmente são carentes de qualquer possibilidade de observar e controlar, caso por caso, tal execução e seus efeitos"(40). Por outro lado, segue o autor, retomando um argumento de Michell, "a 'impotência' relativa dos tribunais 'de executarem a sua vontade', por exemplo, é vista por alguns como 'uma fonte de força', antes que de fraqueza, pois induz os juízes a 'comandar convencendo, em vez de constrangendo(41)'”. Desta forma, o autor conclui que "a produção judiciária do direito, nada obstante todas as limitações que Ihe são inerentes e das quais já falei, não é em absoluto antidemocrática por si mesma ${ }^{(42) "}$. Tate e Vallinder ${ }^{(43)}$, numa perspectiva semelhante, afirmam que, embora a expansão do Poder Judiciário não seja uma condição necessária para um país consolidar sua democracia, dependendo das circunstâncias, ela tem sido considerada inevitável, principalmente em países de construção democrática recente, como o caso do Brasil.

\section{DOIS EIXOS PARA A INTERPRETAÇÃO DA JUDICIALIZAÇÃO}

Na obra "Judicialização da política e das relações sociais no Brasil", Vianna e colaboradores ${ }^{(44)}$ discutem a judicialização a partir de dois eixos interpretativos. O primeiro deles, o eixo procedimentalista, representado por Habermas e Garapon, afirma que este fenômeno contribui para a diminuição (ou privatização) da cidadania. Na interpretação de Vianna et al sobre Garapon, "a judicialização da política e do social seria, então, um mero indicador de que a justiça se teria tornado um último refúgio de um ideal democrático desencantado"(45). Da mesma forma, "a judicialização da sociedade desinsti-

(39) CAPPELLETTI, Mauro. op. cit.

(40) Id. Ibid., p. 87.

(41) Id. Ibid., p. 90.

(42) Id. Ibid., p. 106.

(43) TATE, C. Neal; VALLINDER, Torbjorn, (Org.). op. cit.

(44) VIANNA, Luiz Jorge Werneck; BURGOS, Marcelo Baumann, op. cit.

(45) Id. Ibid., p. 25. 
tucionalizaria a democracia, marginalizando as instituições de mediação as associações e os partidos políticos ${ }^{(46) "}$.

No segundo eixo, o substancialista, representado por Cappelletti e Dworkin - ainda de acordo com os autores - , a judicialização é tratada, diferentemente do eixo anterior, como uma extensão da democracia e uma ampliação da cidadania. Para Cappelletti(47), "o Poder Judiciário pode contribuir para o aumento da capacidade de incorporação do sistema político, garantindo a 'grupos marginais', destituídos de meios para acessar 'os poderes políticos', uma oportunidade para a vocalização de suas expectativas de direito". Numa perspectiva mais ampla, "a política se judicializa a fim de viabilizar o encontro da comunidade com os seus propósitos, declarados formalmente na Constituição"(48). Nesta mesma linha, Eisenberg ${ }^{(49)}$ afirma que a judicialização da política, "precisa ser avaliada em termos de sua finalidade".

A fim de ampliar a perspectiva adotada neste segundo eixo de interpretação, convém resgatar, conforme Viana e Burgos ${ }^{(50)}$, a idéia de cidadania complexa, na qual estão presentes tanto a clássica concepção de cidadania política, representada formalmente pelos ritos eleitorais, como uma "cidadania social".

"Verifica-se que a pluralização da soberania tem coincidido com a ampliação dos níveis de representação, que passam a compreender, além dos representantes do povo por designação eleitoral, os que falam, agem e decidem em seu nome, como a magistratura e as diversas instâncias legitimadas pela lei a fim de exercer funções de regulação(51)".

Justamente por agregar características de uma representatividade política e judicial, a cidadania complexa não diminuiria a participação e a influência da sociedade no processo político, mas, ao contrário, expandiria suas possibilidades de influência e de inserção na condução da política, contribuindo para concretizar a própria "supremacia do povo soberano sobre os poderes que são exercidos em seu nome, dado que o povo somente pode exercer controle sobre seus representantes por meio de uma outra representação"(52). De um lado, a cidadania política permite a participação dos cidadãos nos procedimentos democráticos que levam à formulação da lei; por outro, a cidadania social fornece a esses cidadãos a possibilidade de reivindicarem judicialmente a aplicação da lei. No caso brasileiro, isto se verifica, por exemplo, a partir das instituições da Ação Civil Pública e do Mandado de

(46) VIANNA, Luiz Jorge Werneck; BURGOS, Marcelo Baumann. op. cit., p. 26.

(47) CAPPELLETTI, Mauro. op. cit.,p. 34.

(48) Id. Ibid., p. 40.

(49) EISENBERG, José, op. cit., p. 46.

(50) VIANNA, Luiz Jorge Werneck; BURGOS, Marcelo Baumann, op. cit., p. 370.

(51) Id. Ibid., p. 170.

(52) Id. Ibid., p. 366. 
Segurança (este segundo visa garantir um direito líquido e certo "negado" pelas autoridades competentes). Este processo caracteriza-se por proporcionar uma dupla inserção na vida pública dos homens comuns, ampliando, portanto, as estratégias de acesso à coisa pública.

Os autores recordam que a Constituição Brasileira "prevê a participação, entre outras, da sociedade civil organizada e do Ministério Público no controle da constitucionalidade das leis. ${ }^{(53)}$ A fim de concluir este ponto, vale recorrer mais uma vez à citação dos autores:

“Não se trata, pois, de uma 'migração' do lugar da Democracia para o da Justiça, mas de sua ampliação pela generalização da representação, que pode ser ativada tanto pela cidadania política nas instituições clássicas da soberania quanto pela 'cidadania social'."(54)

A cidadania complexa possibilitou a inclusão de diversos segmentos e grupos da sociedade civil que antes se viam completamente distantes da participação social. E, na medida em que agora uma parte significativamente maior da sociedade participa da criação dos direitos, dos quais são seus destinatários, fixa e alarga ainda mais o campo dos direitos já declarados ${ }^{(55)}$. Isto é importante na medida em que compreendemos, por exemplo, a saúde como algo específico a um dado momento histórico e social. E com a garantia dos direitos básicos nesta área, é possível começar a pensar na própria ampliação destes direitos, seja por via legislativa, ou judicial. "Pode-se sustentar, portanto, que a conquista de direitos ainda ignorados e a luta pela preservação dos direitos já declarados são processos que se reforçam mutuamente."(56)

A conquista de novos direitos no campo da saúde é um processo potencialmente viável e vem ocorrendo, na medida em que o conteúdo das leis neste campo é amplo e geralmente indeterminado, a exemplo da controversa discussão a respeito da inserção no orçamento da saúde de medidas de combate à fome. A grande "abertura" que compõe o texto da saúde na Constituição de 1988 criou no Brasil um duplo movimento. Inicialmente, os "conceitos jurídicos indeterminados" eram insuficientes para garantirem oferta de bens e serviços de saúde à população brasileira. Em um momento seguinte, essa mesma indeterminação foi usada como artifício para a garantia do direito à saúde. Neste meio tempo, é latente a mudança de postura do Poder Judiciário brasileiro, que deixou de ser uma tímida instituição, para assumir um papel de destaque no setor saúde ${ }^{(57)}$. Isto ocorreu no sentido de que "quanto mais

(53) VIANNA, Luiz Jorge Werneck; BURGOS, Marcelo Baumann. op. cit., p. 371.

(54) Id. Ibid., p. 371.

(55) Id. Ibid., p. 374.

(56) Id. Ibid., p. 374.

(57) Se encararmos o exemplo da participação dos movimentos sociais na definição da política nacional de AIDS sob a perspectiva apontada, percebe-se claramente a atuação do Poder Judiciário 
vaga a lei e mais imprecisos os elementos do direito, mais amplo se torna também o espaço deixado à discricionariedade nas decisões judiciais"(58)(59).

Esta perspectiva pode ser associada à idéia de "direito responsivo", apresentada por Nonet e Selznick ${ }^{(60)}$ pelo prisma da abertura do Direito às necessidades sociais. Para estes autores, o estágio do direito responsivo torna o direito mais aberto e mais responsável pelas necessidades sociais, oferecendo algo a mais do que uma justiça procedimental, paradigma que eles denominam "Direito Autônomo". Pela via do direito responsivo, "as instituições legais desistiram da segurança insular do direito autônomo e tornaram-se instrumentos mais dinâmicos da ordem social e da mudança social. Nesta reconstrução, o ativismo, a abertura e a competência cognitiva combinam-se como motivos básicos"(61). Por outro lado, alertam os autores, a abertura provocada por este tido de direito só é possível numa sociedade com um patamar mínimo de igualdade entre os cidadãos, caracterizado por um elevado grau de consciência política, educação, bem como por costumes estabelecidos de ativismo e participação social. A atuação do Poder Judiciário e a adoção de meios jurídicos na formação de políticas de saúde aconteceram, portanto, juntamente com o desenvolvimento de algumas destas características na população (ou de uma parcela desta, mais bem organizada), sobretudo, com o amadurecimento da participação de amplos setores da sociedade na elaboração das políticas públicas de saúde.

\section{CONSIDERAÇÕES FINAIS}

Antes de nos apressarmos em apontar uma opinião definitiva sobre o fenômeno da judicialização das políticas de saúde coletiva no Brasil, talvez seja necessário retomar algumas das principais hipóteses que delineiam o atual debate acerca da judicialização da política e da sociedade. Inicialmente, tomemos em consideração as proposições ${ }^{(62)}$ de Vianna e Burgos ${ }^{(63)}$, de que a judicialização seria uma extensão da democracia e uma ampliação da cidadania. A fim de validarmos esta hipótese, devemos verificar se, como

como definidor de prioridades e, no limite, como legislador. A questão subjacente a esta atuação diz respeito à legitimidade do Poder Judiciário intervir sobre a própria alocação orçamentária definida pelo Legislativo e o Executivo. Retomaremos este ponto mais à frente.

(58) VIANNA, Luiz Jorge Werneck; BURGOS, Marcelo Baumann. op. cit., p. 27.

(59) Para Cappelletti (op. cit., p. 102) "a lei é um mito, que deve ser interpretada e completada para traduzir-se em ação real e que a interpretação judiciária, mesmo tendo por objeto a lei, em certa medida é sempre criativa do direito".

(60) NONET, Philippe; SELZNICK, Philip; KAGAN, Robert; KAGAN, Robert A. Law and society in transition: Toward Responsive Law. New York: Octagon Books, 1978. p. 130 p.

(61) Id. Ibid., p. 74.

(62) Tal como apresentado anteriormente na exposição do eixo substancialista.

(63) VIANNA, Luiz Jorge Werneck; BURGOS, Marcelo Baumann, op. cit. 
decorrência do processo de judicialização, ampliou-se a incorporação de "grupos marginais" no sistema político, tal como nos sugere Cappelletti ${ }^{(64)}$, ou se, caso contrário, ao invés de garantir direito, a judicialização, não estaria contribuindo para intensificar a assimetria de direitos na sociedade brasileira. Evidentemente, poder-se-ia pensar numa terceira possibilidade, qual seja, de que a judicialização na saúde contribuiria tanto para a incorporação de grupos marginais no sistema político como para a intensificação da assimetria de direitos. Neste caso, seria preciso ainda calcular em que proporção cada um destes fenômenos ocorre, de forma tal que possamos constatar em que medida eles constituem uma tendência do processo de judicialização no campo da saúde.

Tate $^{(65)}$, ao descrever as condições necessárias para a existência da judicialização, afirma que este não é um fenômeno isolado dos interesses econômicos que estruturam o sistema político. O autor está atento para o fato de que a expansão da política de direitos pode ser mais apropriadamente definida conforme o sucesso de certos grupos de interesse em alcançar seus objetivos fora do processo majoritário de decisão política. Determinados grupos têm descoberto a cada dia o potencial dos tribunais atenderem às suas reivindicações correlacionando-as a direitos formalmente garantidos pela Constituição. Este aspecto pode ser uma das principais forças que têm levado a ampliação do Poder Judiciário no campo da saúde no Brasil.

De modo geral, as ações na justiça pleiteiam medicamentos. Entretanto, muitos desses medicamentos não compõem a lista fornecida pelo SUS e outros não têm autorização da Agência Nacional de Vigilância Sanitária (ANVISA) para circularem no Brasil. Autorizar a aquisição de um medicamento que conste na lista da ANVISA, mesmo com valor elevado, leva o Judiciário a aproximar os direitos do cidadão de sua realidade concreta; por outro lado, autorizar a compra pelo poder público de um medicamento ou de qualquer insumo da saúde não regulamentado no Brasil, transforma o Judiciário muito mais num vocalizador de minorias privilegiadas do que num parceiro dos "grupos marginais".

$\mathrm{Na}$ medida em que os juízes concedem liminares para a aquisição imediata de bens ou serviços de saúde, que devem ser adquiridos pelo Poder Executivo (sob o risco de prisão para o gestor), em geral sem licitação, eles intervêm diretamente na alocação orçamentária, determinada pelo Poder Legislativo, e na condução da política pública de saúde, estabelecida pelo Poder Executivo. Segundo Borges ${ }^{(66)}$, o principal problema "surge quan-

(64) CAPPELLETTI, Mauro, op. cit.

(65) TATE, C. Neal, op. cit., p. 30.

(66) BORGES, Danielle da Costa Leite. Uma análise das ações judiciais para o fornecimento de medicamentos no âmbito do SUS: o caso do Estado do Rio de Janeiro no ano de 2005. Dissertação (Mestrado). Escola Nacional de Saúde Pública, Fundação Oswaldo Cruz, 2007. 
do a saúde se apresenta como um bem particular, ou em termos jurídicos, como um direito subjetivo público. Nessas situações, o exercício do direito subjetivo contra o Estado por determinado indivíduo poderá afetar o exercício do direito subjetivo de outros cidadãos, constituindo-se nesses casos como um bem exclusivo e de consumo rival"(67). Segundo o argumento da autora, a saúde deixaria de ser um direito de cidadania garantido a toda população para transformar-se num bem particular de consumo exclusivo disputado por todos os cidadãos.

Em todo o caso, não se pode perder de vista a possibilidade da atuação do Poder Judiciário servir para pressionar os demais Poderes a atender as necessidades latentes da sociedade brasileira. Como ocorreu na política de AIDS, a judicialização pode contribuir para o alargamento das ações e serviços disponibilizados pelo Estado e para a própria revisão da política que vem se desenvolvendo.

Nesta breve aproximação teórica com o tema, pode-se perceber que há evidências tanto positivas como negativas do processo de expansão do Poder Judiciário. A adoção da política de AIDS claramente representa o primeiro grupo. Por outro lado, há indícios de que a compra de determinados insumos possa desvirtuar os aspectos benéficos da judicialização. A abordagem teórica tem o mérito de lançar luz sobre essas duas tendências possíveis do processo de judicialização. Neste sentido, as teorias sobre a expansão do Poder Judiciário têm se mostrado bastante frutíferas na elaboração de questões importantes pertinentes ao debate sobre a necessidade de ampliação da cidadania nos Estados de Direito contemporâneo. No entanto, somente estudos empíricos serão capazes de desvendar os rumos concretos que o processo de judicialização tem tomado, uma vez que ele é condicionado por inúmeros outros fatores extrajudiciais, tais como grau de desigualdade social, nível de escolaridade e mobilização política da população que demanda ações na justiça.

\section{REFERÊNCIAS BIBLIOGRÁGICAS}

ARANTES, Rogério Bastos. Direito e política: o Ministério Público e a defesa dos direitos coletivos. Revista Brasileira de Ciências Sociais, Rio de Janeiro, v. 14, n. 39, p. 83-102, 1999.

BORGES, Danielle da Costa Leite. Uma análise das ações judiciais para o fornecimento de medicamentos no âmbito do SUS: o caso do Estado do Rio de Janeiro no ano de 2005. Dissertação (Mestrado). Escola Nacional de Saúde Pública, Fundação Oswaldo Cruz, 2007.

(67) BORGES, Daniele da Costa Leite. op. cit., p. 23. 
CAPPELLETTI, Mauro. Juízes Legisladores? Porto Alegre: Sergio Antonio Fabris Editor, 1993. 134 p.

CITTADINO, Gisele. Judicialização da política, constitucionalismo democrático e separação dos poderes. In: VIANNA, Luiz Jorge Werneck (Org.). A democracia e os três poderes no Brasil. Belo Horizonte: UFMG, 2002. p. 17-41.

CONSTITUIÇÃO FEDERAL, Brasil, 1988.

DALLARI, S. G. Uma nova disciplina: o direito sanitário. Revista de Saúde Pública, São Paulo, v. 22, n. 4, p. 327-334, 1998.

EISENBERG, José. Pragmatismo, direito reflexivo e judicialização da política. In: VIANNA, Luiz Jorge Werneck (Org.). A democracia e os três poderes no Brasil. Belo Horizonte: UFMG, 2002. p. 43-61.

GOUVÊA, Marcos Masilli. O direito ao fornecimento estatal de medicamentos. Revista Forense, Rio de Janeiro, v. 370, p. 103-134, 2003.

MACHADO, Felipe Rangel de Souza, Direito à saúde, integralidade e participação: um estudo sobre as relações entre Sociedade e Ministério Público na experiência de Porto Alegre. Dissertação (Mestrado). Instituto de Medicina Social, Universidade do Estado do Rio de Janeiro, Rio de Janeiro, 2006.

MACIEL, Débora Alves; KOERNER, Andrei. Sentidos da judicialização da política: duas análises. Lua Nova, São Paulo, n. 57, p. 113-133, 2002.

MELAMED, Clarisse; RIBEIRO, José Mendes. O inquérito civil público sobre a Saúde. ENSP/FIOCRUZ, 1995.

MESSEDER, Ana Márcia; OSORIO-DE-CASTRO, Cláudia Garcia Serpa; LUIZA, Vera Lúcia. Mandados judiciais como ferramenta para garantia do acesso a medicamentos no setor público: a experiência do Estado do Rio de Janeiro. Cadernos de Saúde Pública, Rio de Janeiro, v. 21, n. 2, p. 525-534, 2005.

NONET, Philippe; SELZNICK, Philip; KAGAN, Robert; KAGAN, Robert A. Law and society in transition: Toward Responsive Law. New York: Octagon Books, 1978. $130 \mathrm{p}$.

TATE, C. Neal. Why the Expansion of Judicial Power? In: ; VALLINDER, Torbjorn. (Org.) The global expansion of judicial power. New York, London: New York University Press, 1995. p. 27-37

TORRES-FERNANDES, Marilia de Castro. Ministério Público em São Paulo: eficácia da função institucional de zelar pelo direito à saúde. Dissertação (Mestrado), Universidade de São Paulo, São Paulo, 1999. 
VALLINDER, Torbjorn. When the courts go marching. In: TATE, C. Neal; VALLINDER, Torbjorn (Org.). The global expansion of judicial power. New York, London: New York University Press, 1995. p. 13-26.

VIANNA, Luiz Jorge Werneck; BURGOS, Marcelo Baumann. Revolução processual do direito e democracia progressiva. In: VIANNA, Luiz Jorge Werneck. (Org.). A democracia e os três poderes no Brasil. Belo Horizonte: UFMG, 2002. p. 337-491.

VIANNA, Luiz Jorge Werneck; MELO, Manuel Palácios Cunha; CARVALHO, Maria Alice Rezende de; BURGOS, Marcelo Baumann. Corpo e alma da magistratura brasileira. Rio de Janeiro: Revan, 1997. 336 p. 